\title{
Simulation of breaking waves over different seabed configurations using phase-resolving wave models
}

\author{
RS Ranasinghe \\ Department of Civil Engineering, Faculty of Engineering Technology, The Open University of Sri Lanka, Nawala.
}

\begin{abstract}
The applicability of two phase-resolving wave models (Boussinesq-type) for simulating wave transformation over seabeds with plane slopes and with submerged structures is further investigated by coupling a turbulent kinetic energy (TKE) equation for wave breaking induced energy dissipation. Previous studies have shown that the models developed using Boussinesq equations with improved nonlinearity and frequency dispersion are capable of simulating wave evolution over mildly sloping beaches at shallow/intermediate water depths but with little emphasis on changes to bottom configurations. In this study, a published set of data is used to calibrate two phaseresolving wave models developed extending an improved form of the Boussinesq equations to include steep localised bottom slopes and wave breaking induced energy dissipation. The first model is limited to simulating wave transformation over impermeable beds but the second model is developed to incorporate porous beds. Porous damping is introduced in the second model by coupling the governing equations with a nonlinear Darcy-Forchheimer equation. The calibrated models with appropriate values for relevant model parameters are found to reproduce wave height, mean water level distributions across the surf zone for different wave conditions and bottom configurations with a high-level of accuracy in 1-dimensional horizontal (1DH) wave propagation. The results obtained from this study are vital in validating a 2-dimensional horizontal (2DH) wave-current model.
\end{abstract}

Keywords: Boussinesq model, eddy viscosity, energy dissipation, turbulent kinetic energy, wave breaking.

\section{INTRODUCTION}

Over the years, researchers have continuously made contributions to the development and enhancement of mathematical theories for wave propagation (such as Boussinesq equations, energy balance equation, mild slope equation and RANS equations), and described wave evolutions due to various phenomena in the nearshore. Out of those main wave equations, Boussinesq-type equations (phase-resolving) have made a remarkable development over the last couple of decades largely due to the critical steps provided by Madsen et al. (1991) and Nwogu (1993). Equations by Madsen et al. (1991) were further extended in Madsen and Sorensen (1992) to include terms proportional to the bottom slope, which are essential for demonstrating shoaling characteristics of waves. Most of the subsequent theories, which were developed to extend the nonlinearity and frequency dispersion properties (Wei et al., 1995; Madsen et al., 1996; Madsen \& Schäffer,1998; Zou, 1999; Gobbi et al., 2000; Chen et al., 2003; Schäffer, 2004; Li, 2008; Karambas \& Memos 2009; Chondros \& Memos, 2014) were based on Madsen and Sorensen (1992) and Nwogu (1993) platform equations. Furthermore, the incorporation of porous flow resistance in Boussinesqtype models were performed by Cruz et al. (1997), Hsiao et al. (2002), Garcia et al. (2004), Chen (2006) and Cruz and Chen (2007) and this has enabled the application of such models for simulating wave propagation over permeable beds and submerged bars. However, these models are primarily limited to non-breaking wave dissipation over permeable beds; therefore, appropriate wave breaking sub-models are necessary to be incorporated to investigate wave breaking induced energy dissipation over such bottom configurations.

\footnotetext{
*Corresponding author (rsran@ou.ac.lk; (DD https://orcid.org/0000-0003-1168-0577)
} 
Modelling surf zone hydrodynamics is of great interest for many reasons. Although wave breaking is the most dominant driving mechanism for the current generation and subsequently the sediment transport in the coastal zone, due to highly nonlinear and turbulent nature of the flow, a full mathematical description of the complex hydrodynamics in the surf zone is difficult. Most of the wave theories, including Boussinesq-type, are obtained under the hypothesis of ideal and irrotational flow which restricts the direct incorporation of production and evolution of vorticity within the equations. In order to overcome this limitation, some closure models have been coupled to Boussinesq equations by researchers to simulate wave breaking and breaking induced energy dissipation. These include reasonably ad hoc additions of eddy viscosity formulations up to reasonably detailed calculations of the generation and transport of turbulent kinetic energy under the breaking wave crest or the surface rollers. Regardless of the formulation, each of the approaches can be thought of as a means of adding the breaking wave force (momentum mixing) terms to the momentum equations. At a minimum, these terms are scaled similarly in order to reproduce the correct amount of energy dissipation. They are also be localised in the front face of the breaking wave, in order to provide the correct distribution of dissipation (Kirby, 2003). All these models differ on how they treat the onset and cessation of wave breaking and the rate of energy dissipation. It is also noted here that Boussinesq equations are depthintegrated equations, which limit the simulation of eddy viscosity distributions over the depth.

The first attempt to simulate wave breaking in a phase resolving model was proposed by Zelt (1991) by introducing a wave force term in the momentum equation. The term regulates the amount of energy dissipation produced by wave breaking and is related to the distribution of eddy viscosity. In the eddy viscosity formulation, to initiate and terminate the wave breaking process, some breaking detection criterion was used. Following Zelt (1991), Kennedy et al. (2000) proposed a new eddy viscosity formulation but with extensions to provide a more realistic description of the onset and cessation of breaking. However, in their formulation, no direct physical meaning can be attributed to the mixing length coefficient and quantities which govern the onset and cessation of breaking.

A simplified formulation with a more direct physical interpretation was developed and introduced into Boussinesq equations by Shaffer et al. (1993) using the surface roller concept of Svendsen (1984). They determined the variation of surface roller in space and time by adopting the heuristic geometrical approach of Deigaard (1989) with some modifications. A strong analogy can be found between Shaffer et al. (1993) and Kennedy et al. (2000) but, as it is the case with Kennedy et al. (2000), onset and cessation of wave breaking and dissipation in Shaffer et al. (1993) formulations depend on a number of parameters, which need calibration. Hence, the setting of appropriate values for these thresholds and determination of temporal and spatial evolution of surface rollers are still challenges to coastal engineering researchers.

Nwogu (1996) extended the fully nonlinear Boussinesq equations of Wei et al. (1995) to surf zone by introducing a term representing vertical gradient in shear stress due to breaking induced turbulent velocity fluctuations in the momentum equations. In this study, a semi-empirical turbulence closure model was used to relate the turbulence stresses to the wave orbital velocities. Following Boussinesq eddy viscosity concept, the turbulence shear stresses were approximated to be proportional to velocity gradients in vertical directions (proportionality coefficient being the eddy viscosity). This resulted in an energy dissipation term equivalent to the one proposed by Zelt (1991). However, in Nwogu (1996) formulations, the eddy viscosity is related to the turbulent kinetic energy and a turbulence length scale. Although the number of free parameters in the turbulent kinetic energy equation is relatively less, there is still an ambiguity in defining an appropriate value for the turbulence length scale (mixing length).

A few studies can be found in the literature on modelling of breaking waves over permeable bottoms/ structures using Boussinesq-type models. Johnson et al. (2005) used a higher-order Boussinesq-type model in 2DH while Metallinos et al. (2016) used the fully dispersive and highly nonlinear Boussinesq-type model of Chondros and Memos (2014) to simulate the wave propagation over a submerged permeable structure in $1 \mathrm{DH}$. In the presence of permeable structures, both models incorporated two additional terms accounting for the interaction between the wave motion outside and the flow within the rubble mound, one in the continuity equation and one in the momentum equation in accordance to the model's extension provided by Cruz et al. (1997). Both models used lower-order porous damping terms and eddy viscosity production and wave breaking induced energy dissipation simulations were performed using formulations proposed by Kennedy et al. (2000). 
In the present study, the wave transformation in nearshore is modelled using a truncated form of Chen (2006) and Nwogu (1993) Boussinesq-type wave equations coupled with one-equation turbulence model (Nowgu, 1996) type) to determine the temporal and spatial evolution of the turbulent kinetic energy produced by wave breaking. Nwogu (1996), Tajima et al. (2007), Ranasinghe et al. (2009a, 2011), Siddique et al. (2017) and Ranasinghe (2018) followed a similar approach for wave breaking induced energy dissipation over plane seabed slopes and seabeds with submerged structures; however, all used values for mixing length which are specific to the cases they studied. BOUSS-2D, a Boussinesq wave model developed to simulate waves and currents in nearshore regions and harbours by US Army Corps of Engineers (Nwogu \& Demirbilek, 2001) too employs a TKE equation for wave breaking induced energy dissipation and recommends a value equal to water wave height for mixing length but with no emphasis on any variation due to bottom configuration or wave period. Hence, considering the ambiguities in setting appropriate values for wave breaking parameters for this type of numerical model, an attempt is made in this study to revisit the incorporation of TKE equation for eddy viscosity formulation, set a simple wave breaking detection criterion for two weakly nonlinear Boussinesqtype models, and propose an appropriate representation for mixing length using a published set of data covering plane seabed slopes and seabeds with submerged structures for 1-dimensional horizontal (1DH) wave propagation. These results are expected to be used to validate a 2-dimensional horizontal (2DH) Boussinesqtype wave-current model.

\section{METHODOLOGY}

\section{The governing equations}

Although a number of upgrades have been developed over the past two decades, still Nwogu (1993) and Madsen and Sorensen (1992) Boussineq-type equations are preferred and used for commercial purposes in nearshore wave current modelling due to simplicity and stability of these models when used to simulate waves and currents over mildly sloping impervious beaches. The models developed with fully nonlinear dispersive Boussinesq-type equations or Navier-Stokes equations are difficult to be deployed in practical applications due to stability issues and very high computational cost.

As highlighted earlier, a truncated form of Chen (2006) and Nwogu (1993) Boussinesq-type equations are used for the investigations in the present study. The truncated Chen (2006) equations are analogous to Nwogu (1993) equations when porous damping terms are switched off. A short description of the governing equations and different sub-models used in the two models is presented below.

In one horizontal dimension (1DH), the truncated form of Chen (2006) equations (i.e. by dropping higherorder nonlinear and porous damping terms) read as:

\section{Continuity equation:}

$\eta_{t}+\left(M+n M^{s}\right)_{x}=0$

where,

$M=(h+\eta)\left\{u^{\alpha}+a_{1} h^{2} u_{x x}^{\alpha}+a_{2} h\left[\left(h u^{\alpha}\right)_{x x}+n\left(h_{s} u^{\beta}\right)_{x x}\right]\right\}$

$M^{s}=\left(h_{s} u^{\beta}\right)_{x}+\left[h_{s}^{2}\left(a_{3} h_{s}-a_{4} h\right) u_{x x}^{\beta}\right]_{x}+\left[a_{4} h_{s}^{2}\left(h_{b} u^{\beta}\right)_{x x}\right]_{x}$

$a_{1}=\frac{1}{2} \alpha^{2}-\frac{1}{6}, a_{2}=\alpha+\frac{1}{2}, a_{3}=\frac{1}{2} \beta^{2}-\frac{1}{6}, a_{4}=\beta+\frac{1}{2}$,

$\alpha=\frac{z_{\alpha}}{h}, \beta=\frac{\left(z_{\beta}+h\right)}{h_{s}}$

Momentum equation for clear water:

$$
\begin{gathered}
u_{t}^{\alpha}+u^{\alpha} u_{x}^{\alpha}+g \eta_{x}+b_{1} h^{2} u_{x x t}^{\alpha}+b_{2} h\left(h u^{\alpha}\right)_{x x t} \\
+n b_{2} h\left(h_{s} u^{\beta}\right)_{x x t}=0 \\
b_{1}=\frac{1}{2} \alpha^{2}, \quad b_{2}=\alpha
\end{gathered}
$$

Momentum equation for porous layer:

$$
\begin{aligned}
& u_{t}^{\beta}+u^{\beta} u_{x}^{\beta}+g \eta_{x}+\frac{z_{\beta}^{2}}{2} u_{x x t}^{\beta}+z_{\beta}\left(h_{b} u^{\beta}\right)_{x x t}+\frac{1}{2}\left(h^{2} u_{x t}^{\alpha}\right)_{x}- \\
& \frac{1}{2}\left(h^{2} u_{x t}^{\beta}\right)_{x}+\left[h\left(h_{b} u_{t}^{\beta}\right)_{x}\right]_{x}+R^{\beta}\left[u^{\beta}+\frac{z_{\beta}^{2}}{2} u_{x x}^{\beta}+z_{\beta}\left(h_{b} u^{\beta}\right)_{x x}\right]
\end{aligned}
$$


where $n$ is the porosity of the porous material, $\eta$ is the free water surface elevation, $h$ is the clear water depth, $h_{s}$ is the porous layer depth, $h_{b}\left(h+h_{s}\right)$ is the total water depth $u^{\alpha}$ is the water particle velocity at reference water depth $z_{\alpha}$, and $u^{\beta}$ is the water particle velocity at reference water depth $z_{\beta}$ inside porous layer along the wave propagation direction (Figure 1). The factors, $\alpha$ and $\beta$ are determined by matching dispersion characteristics of wave motion in both clear water and porous layer (not discussed in this paper). $R^{\beta}$ is the porous resistance force evaluated at $z=z_{\beta}$ as follows;

$R^{\beta}=a_{P}+b_{P} u^{\beta}+C_{A} \frac{\partial}{\partial t}$

where $a_{P}$ and $b_{P}$ are respectively, the linear and nonlinear porous resistance coefficients, and $C_{A}$ is the added mass coefficient. The porous resistance coefficients are estimated from the following relationships following Sollitt \& Cross (1972):

$a_{P}=\frac{n v}{K_{P}}, \quad b_{P}=\frac{C_{f} n^{2}}{\sqrt{K_{P}}}$

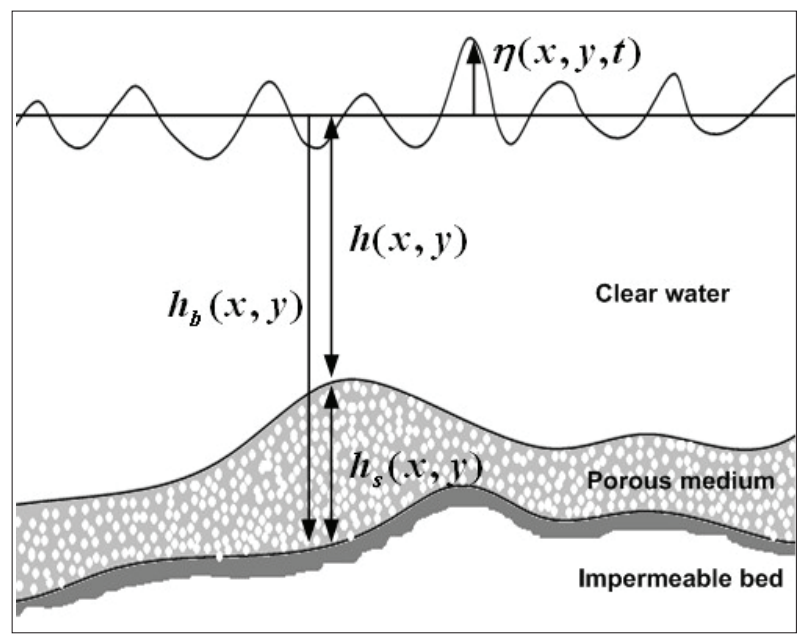

Figure 1: Definition sketch of variables associated with wave transformation over porous beds (Ranasinghe et al., 2009b)

where $v$ is the kinematic viscosity of water $\left(\sim 10^{-6} \mathrm{~m}^{2} / \mathrm{s}\right)$. The intrinsic permeability, $K_{P}$. added mass coefficient, $C_{A_{i}}$ and nonlinear drag coefficient, $C_{f}$, are determined by empirical formulae proposed by van Gent (1995).
$K_{P}=\frac{d_{50}^{2} n^{3}}{\alpha_{P}(1-n)^{2}}, C_{A}=C_{m} \frac{(1-n)}{n}, C_{f}=\beta_{P} \frac{(1-n)}{n} \frac{\sqrt{K_{P}}}{d_{50}}$

where $d_{50}$ is the median diameter of the porous material, $\alpha_{P}, \beta_{P}$ and $C_{m}$ are empirical coefficients that, in principle, are determined by experiments. However, van Gent (1995) concluded that, although the coefficients $\alpha_{p}$ and $\beta_{p}$ depend on the parameters like shape, aspect ratio or the orientation of the porous material, the values 1000 and 1.1 can be used respectively, if the characteristic length scale $d_{50}$ is used to define the size of porous material. In addition, he suggested using a constant value (0.34) for empirical coefficient, $C_{m}$ for simplicity neglecting the complex dependency of coefficient, $C_{A}$ on the flow field. The porosity, $n$ of the porous material used in the present study was found to be 0.44 .

The above equations yield to Nwogu (1993) Boussinesq-type equations when the porous damping terms are ignored. i.e.,

Continuity equation:

$\eta_{t}+\left\{(h+\eta)\left[u^{\alpha}+a_{1} h^{2} u_{x x}^{\alpha}+a_{2} h\left(h u^{\alpha}\right)_{x x}\right]\right\}_{x}=0$

Momentum equation for clear water:

$u_{t}^{\alpha}+u^{\alpha} u_{x}^{\alpha}+g \eta_{x}+b_{1} h^{2} u_{x x t}^{\alpha}+b_{2} h\left(h u^{\alpha}\right)_{x x t}=0$

\section{Energy dissipation due to friction and wave breaking}

Two additional terms are introduced into momentum conservation equation [Equation 6 when Chen (2006) type is used and Equation 13 when Nwogu (1993) type is used] to simulate the dissipation of wave energy due to bottom friction and wave breaking, which are represented by $F_{f}$ and $R_{b}$, respectively.

$$
F_{f}=\frac{1}{(h+\eta)} f_{w} u^{b}\left|u^{b}\right|
$$

where $f_{w}$ is the wave friction factor, and $u^{b}$ is the near-bottom wave orbital velocity along the $\mathrm{x}$-axis. Following Kennedy et al. (2000), a simple eddy 
viscosity type of formulation is adopted to simulate energy dissipation due to wave breaking induced energy dissipation (by introducing the momentum-mixing term into momentum conservation equation in the $\mathrm{x}$-direction).

$R_{b}=\frac{1}{(h+\eta)}\left\{v_{e}\left[(h+\eta) u^{\alpha}\right]_{x}\right\}_{x}$

The rate of wave energy dissipation is expected to be governed by the magnitude of the eddy viscosity, $v_{e}$ , which is related to the turbulent kinetic energy, $k$, and a turbulent length scale, $l_{m}$. The turbulent kinetic energy is determined from a semi-empirical transport equation with a source term for turbulent kinetic energy production by wave breaking, i.e., one equation turbulence closure model (Nwogu (1996):

$$
\boldsymbol{k}_{t}+\boldsymbol{u}^{s} \boldsymbol{k}_{x}=\left(\frac{v_{e}}{\sigma_{k}} k\right)_{x x}+A v_{e}\left[\left(\frac{\partial u}{\partial z}\right)^{2}\right]_{z=\eta}-C_{D} \frac{k^{2 / 3}}{l_{m}}
$$

$$
v_{e}=\sqrt{k} l_{m}
$$

where $u^{s}$ is the free surface wave orbital velocity along the $\mathrm{x}$-axis. The parameter is introduced to ensure that the turbulence is produced only when horizontal velocity at a reference water depth, $u^{s}$, exceeds a threshold velocity (a fraction of the wave celerity, $C)$. The turbulent length scale, $l_{m}$ is to be quantified appropriately as part of the study, while the empirical coefficients, $C_{D}$, and $\sigma_{k}$ for this sub-model are set to be 0.08 and 1 , respectively. To trigger the turbulent kinetic energy equation, an initial estimate of eddy viscosity, $v_{e}$ is necessary, and that is obtained by assuming a local balance between production and dissipation of turbulent kinetic energy as follows:

$$
v_{e}=\frac{l_{m}^{2}}{\sqrt{C_{D}}}\left(\frac{\partial u}{\partial z}\right)_{z=\eta}
$$

\section{Offshore open boundary}

As there is significant wave reflection from submerged breakwaters, it is essential to absorb the waves, which propagate back to wave incident boundary to prevent a build-up of wave energy inside the computational domain. This is achieved with the line boundary method proposed by Ishii et al. (1994). In this method, the neighbouring grid points are divided into two types according to their position with respect to line boundary. Both incident and outgoing waves exist inside line boundary (region 1), whereas only outgoing waves exist outside the line boundary (region 2) as shown in Figure 2. To completely dissipate the energy of outgoing waves, a sponge layer with an adequate width is provided along region 2 .

\section{Abrupt depth variation and shallow freeboards at submerged structures}

Ranasinghe et al. (2009a) artificial energy dissipation term was incorporated when simulating wave transformation over submerged structures to overcome unrealistic flow patterns and numerical instabilities. In addition, considering the bed as permeable with finite

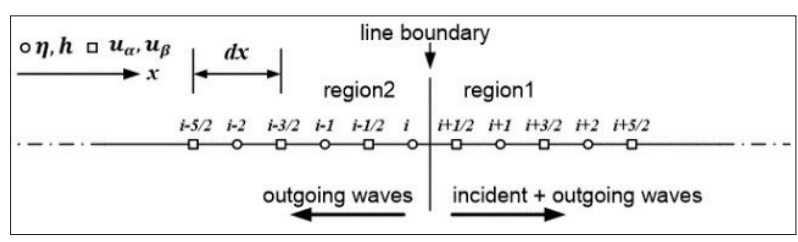

Figure 2: Staggered grid used in the finite difference scheme.

porosity, possible wetting and drying coexisting field (i.e. the wave trough level was allowed to touch the crown of the structure) was allowed in simulations associated with solid submerged structures following Kennedy et al. (2000). However, this was not permitted in simulations associated with porous submerged structures due to the clear existence of water and porous layers in the model.

\section{Numerical scheme}

The truncated Chen (2006) and Nwogu (1993) Boussinesq-type equations are solved in the time domain using a third-order Adams-Bashforth predictor step and a fourth-order Adams-Moulton corrector step. The computational domain is discretised with grid size, in the -direction and the equation variables and are defined at grid points in a staggered scheme as shown in Figure 2. The water depth and surface elevation are defined at grid points, while velocities are defined half a grid point on either side of elevation grid points. The external boundaries of the computational domain correspond to velocity grid points. The first-order spatial derivatives are differenced to, which automatically eliminates error terms that would be of the same form as dispersive terms [Wei \& Kirby (1995)]. The secondorder spatial derivatives are discretized to $O\left(\Delta x^{4}\right)$, while the advection terms are differenced with second-order upwind difference scheme. The computations are carried out for free surface elevation, $\eta$. reference velocity for clear water, $u^{\alpha}$, reference velocity for porous medium, $u^{\beta}$ and turbulent kinetic energy, $k$ simultaneously. 


\section{Experimental set-up}

The numerical models were first validated and then calibrated using a published set of experimental data associated with 15 cases. They included 07, 03, and 05 tests with plane slopes, solid submerged structures and porous submerged structures, respectively. The solid submerged structure models were constructed with concrete and the porous were constructed with gravel of mean diameter $\left(d_{50}\right)$ equal to $12 \mathrm{~mm}$. Figure 3 illustrates the definition of variables associated with the physical models used and Table 1 lists the wave parameters, physical model dimensions and numerical space and time steps associated with all cases considered.

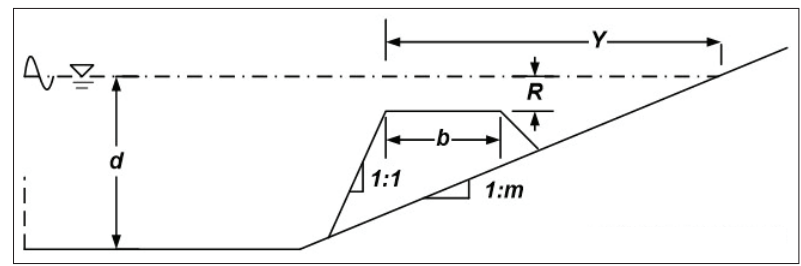

Figure 3: Definition sketch for variables associated with the tests not drawn to scale.

Table 1: Wave parameters, physical model dimensions and numerical model quantities associated with all cases.

\begin{tabular}{|c|c|c|c|c|c|c|c|c|c|c|}
\hline & \multicolumn{3}{|c|}{ Wave parameters } & \multicolumn{4}{|c|}{ Physical model dimensions } & \multicolumn{2}{|c|}{$\begin{array}{l}\text { Space and time steps for } \\
\text { the numerical model }\end{array}$} & \\
\hline Case & & $T(\mathrm{~s})$ & $d(\mathrm{~mm})$ & $m$ & $Y$ & $b$ & $R$ & & & Remarks \\
\hline No. & $(\mathrm{mm})$ & & & & $(\mathrm{mm})$ & $(\mathrm{mm})$ & $(\mathrm{mm})$ & $(\mathrm{mm})$ & (s) & \\
\hline PLS01 & 99 & 1.18 & 400 & $1 / 20$ & - & - & - & 36 & 0.0059 & $\begin{array}{l}\text { Plane slope, Sato et al. } \\
\text { (1988) }\end{array}$ \\
\hline PLS02 & 61 & 1.18 & 400 & $1 / 20$ & - & - & - & 36 & 0.0059 & $\begin{array}{l}\text { Plane slope, Sato et al. } \\
\text { (1988) }\end{array}$ \\
\hline PLS03 & 43 & 1.00 & 300 & $1 / 30$ & - & - & - & 25 & 0.005 & $\begin{array}{l}\text { Plane slope } \\
\text { Ranasinghe (2020) }\end{array}$ \\
\hline PLS04 & 50 & 1.25 & 300 & $1 / 30$ & - & - & - & 25 & 0.00625 & $\begin{array}{l}\text { Plane slope } \\
\text { Ranasinghe (2020) }\end{array}$ \\
\hline PLS05 & 46 & 1.25 & 295 & $1 / 30$ & - & - & - & 25 & 0.00625 & $\begin{array}{l}\text { Plane slope } \\
\text { Siddique et al. (2017) }\end{array}$ \\
\hline PLS06 & 90 & 2.00 & 560 & $1 / 25$ & - & - & - & 100 & 0.01 & $\begin{array}{l}\text { Plane slope } \\
\text { Nwogu (1996) }\end{array}$ \\
\hline PLS07 & 67 & 1.67 & 360 & $1 / 34$ & - & - & - & 50 & 0.00835 & $\begin{array}{l}\text { Plane slope } \\
\text { Hansen and Svendsen (1979) }\end{array}$ \\
\hline SSB01 & 39 & 1.00 & 300 & $1 / 30$ & 2150 & 300 & 10 & 25 & 0.005 & $\begin{array}{l}\text { Solid structure } \\
\text { Ranasinghe et al. (2009a) }\end{array}$ \\
\hline SSB02 & 39 & 1.00 & 300 & $1 / 30$ & 2150 & 300 & 28 & 25 & 0.005 & $\begin{array}{l}\text { Solid structure } \\
\text { Ranasinghe et al. (2009b) }\end{array}$ \\
\hline SSB03 & 48 & 1.25 & 300 & $1 / 30$ & 1950 & 300 & 20 & 25 & 0.00625 & $\begin{array}{l}\text { Solid structure } \\
\text { Ranasinghe (2020) }\end{array}$ \\
\hline PSB01 & 39 & 1.00 & 300 & $1 / 30$ & 2150 & 300 & 28 & 25 & 0.005 & $\begin{array}{l}\text { Porous structure } \\
\text { Ranasinghe } \text { et al. (2009b) }\end{array}$ \\
\hline PSB02 & 35 & 1.00 & 275 & $1 / 30$ & 2850 & 900 & 30 & 25 & 0.005 & $\begin{array}{l}\text { Porous structure } \\
\text { Ranasinghe (2020) }\end{array}$ \\
\hline PSB03 & 36 & 1.25 & 275 & $1 / 30$ & 2850 & 900 & 30 & 32 & 0.00625 & $\begin{array}{l}\text { Porous structure } \\
\text { Ranasinghe (2020) }\end{array}$ \\
\hline PSB04 & 36 & 1.00 & 275 & $1 / 30$ & 2550 & 1650 & 30 & 25 & 0.005 & $\begin{array}{l}\text { Porous structure } \\
\text { Ranasinghe et al. (2009b) }\end{array}$ \\
\hline PSB05 & 42 & 1.25 & 275 & $1 / 30$ & 2550 & 1650 & 30 & 32 & 0.00625 & $\begin{array}{l}\text { Porous structure } \\
\text { Ranasinghe } \text { et al. (2009b) }\end{array}$ \\
\hline
\end{tabular}


A series of numerical simulations were carried out to estimate the best fit for each case by varying the wave breaking detection parameter, $u^{s} / C$ and mixing length, $l_{m}$. Here, the wave celerity, $C$ is determined by linear dispersion relation. The wave breaking detection parameter is vital in the TKE equation as it determines the production of turbulent kinetic energy. The $u^{s} / C$ ratio was varied in intervals of 0.02 starting from 0.60 to 1.00 , while $l_{m}$ was initially varied as a fraction (in intervals of 0.25 from 0.25 to 1.50 ) of the incident wave height making the total number of simulation runs for an individual case equal to 126 . All the physical and numerical models were tested with regular waves only.

\section{RESULTS AND DISCUSSION}

\section{Comparison of measured and simulated quantities}

To investigate the performance of the wave breaking induced energy dissipation sub-model, numerical model results are compared with the measured wave height and mean water level distributions across the surf zone. The overall agreement between measured and simulated values at all gauges is quantified firstly by calculating the Willmott index (Wilmott,1984) given in equation 19 for wave height and mean water level separately and then by taking the product between them.
$I_{W}=1-\frac{\sum_{k=1}^{N}\left(X_{c k}-X_{m k}\right)^{2}}{\sum_{k=1}^{N}\left[\left|X_{c k}-\bar{X}_{m}\right|+\left|X_{m k}-\bar{X}_{m}\right|\right]^{2}}$

In Equation (19), $X_{m}$ denotes the measured values, $X_{c}$ denotes the computed values, $\bar{X}_{m}$ denotes the average measured values, and $N$ is the number of gauges. The Willmott index will take the value of 1.0 for a perfect agreement.

\section{Best overall agreement for individual cases}

Figures 4 and 5 depict, respectively, the computed and measured wave height distributions and mean water level distributions across the surf zone for cases associated with plane seabed slopes. The red lines indicate the profiles associated with the cases related to highest combined Willmott index (i.e. product between Willmott indices for wave heights and for mean water level), whereas the blue lines indicate the profiles associated with the proposed values for model parameters considering the overall agreement of all 7 cases (i.e. using the calibrated model). The numerical model parameters and the Willmott indices for cases associated with the best agreement with the experimental data are listed in Table 2.

The combined Willmott index for best fit is found to

Table 2: Numerical model parameters and Willmott indices associated with the best agreement for individual cases.

\begin{tabular}{|c|c|c|c|c|c|c|c|c|c|}
\hline \multirow[t]{2}{*}{ Case No. } & \multirow[t]{2}{*}{$L_{0}, \mathrm{~mm}$} & \multirow{2}{*}{$\begin{array}{c}\sqrt{H_{i} L_{0}}, \\
\mathrm{~mm}\end{array}$} & \multirow{2}{*}{$\begin{array}{l}l_{m} \\
\mathrm{~mm}\end{array}$} & \multirow{2}{*}{$\frac{u^{s}}{C}$} & \multirow{2}{*}{$\frac{l_{m}}{H_{i}}$} & \multirow{2}{*}{$\frac{l_{m}}{\sqrt{H_{i} L_{0}}}$} & \multicolumn{3}{|c|}{ Willmott Index } \\
\hline & & & & & & & $\begin{array}{l}\text { Wave } \\
\text { Height }\end{array}$ & $\begin{array}{c}\text { Mean Water } \\
\text { Level }\end{array}$ & Combined \\
\hline PLS01 & 2174 & 464 & 75 & 1.00 & 0.75 & 0.16 & 0.9919 & 0.9616 & 0.9538 \\
\hline PLS02 & 2174 & 364 & 46 & 1.00 & 0.75 & 0.13 & 0.9964 & 0.9506 & 0.9472 \\
\hline PLS03 & 1561 & 259 & 54 & 1.00 & 1.25 & 0.21 & 0.9881 & 0.9811 & 0.9694 \\
\hline PLS04 & 2440 & 349 & 38 & 1.00 & 0.75 & 0.11 & 0.9731 & 0.9731 & 0.9469 \\
\hline PLS05 & 2440 & 335 & 35 & 1.00 & 0.75 & 0.10 & 0.9613 & 0.8902 & 0.8557 \\
\hline PLS06 & 6245 & 750 & 135 & 0.68 & 1.50 & 0.20 & 0.9434 & 0.9100 & 0.8585 \\
\hline PLS07 & 4354 & 540 & 67 & 0.72 & 1.00 & 0.12 & 0.8926 & 0.9295 & 0.8297 \\
\hline SSB01 & 1561 & 247 & 20 & 0.68 & 0.50 & 0.08 & 0.9886 & 0.9889 & 0.9776 \\
\hline SSB02 & 1561 & 247 & 29 & 0.82 & 0.75 & 0.12 & 0.9587 & 0.9610 & 0.9213 \\
\hline SSB03 & 2440 & 342 & 24 & 1.00 & 0.50 & 0.08 & 0.9718 & 0.9786 & 0.9510 \\
\hline PSB01 & 1561 & 247 & 20 & 0.68 & 0.50 & 0.08 & 0.9808 & 0.9903 & 0.9713 \\
\hline PSB02 & 1561 & 234 & 18 & 0.68 & 0.50 & 0.07 & 0.9833 & 0.9647 & 0.9486 \\
\hline PSB03 & 2440 & 296 & 36 & 0.70 & 1.00 & 0.12 & 0.9735 & 0.9772 & 0.9513 \\
\hline PSB04 & 1561 & 237 & 18 & 1.00 & 0.50 & 0.08 & 0.9851 & 0.9631 & 0.9487 \\
\hline PSB05 & 2440 & 320 & 32 & 0.92 & 0.75 & 0.10 & 0.9814 & 0.9814 & 0.9631 \\
\hline
\end{tabular}


be less than 0.90 only in cases PLS05, PLS06 and PLS07 demonstrating a high-level accuracy of the model across the values used. The wave breaking detection parameter and mixing length, vary from 0.68 to 1.00 , and from $0.75 \mathrm{H}_{\mathrm{i}}$ to $1.50 \mathrm{H}_{\mathrm{i}}$, respectively across the 7 cases tested with plane seabed slopes.

Figures 6 and 7 depict, respectively, the simulated and measured wave height distributions and mean water level distributions across the surf zone for cases associated with submerged structures (both solid and porous). Similar to the cases with plane seabed slopes, the red lines indicate the profiles associated with the cases

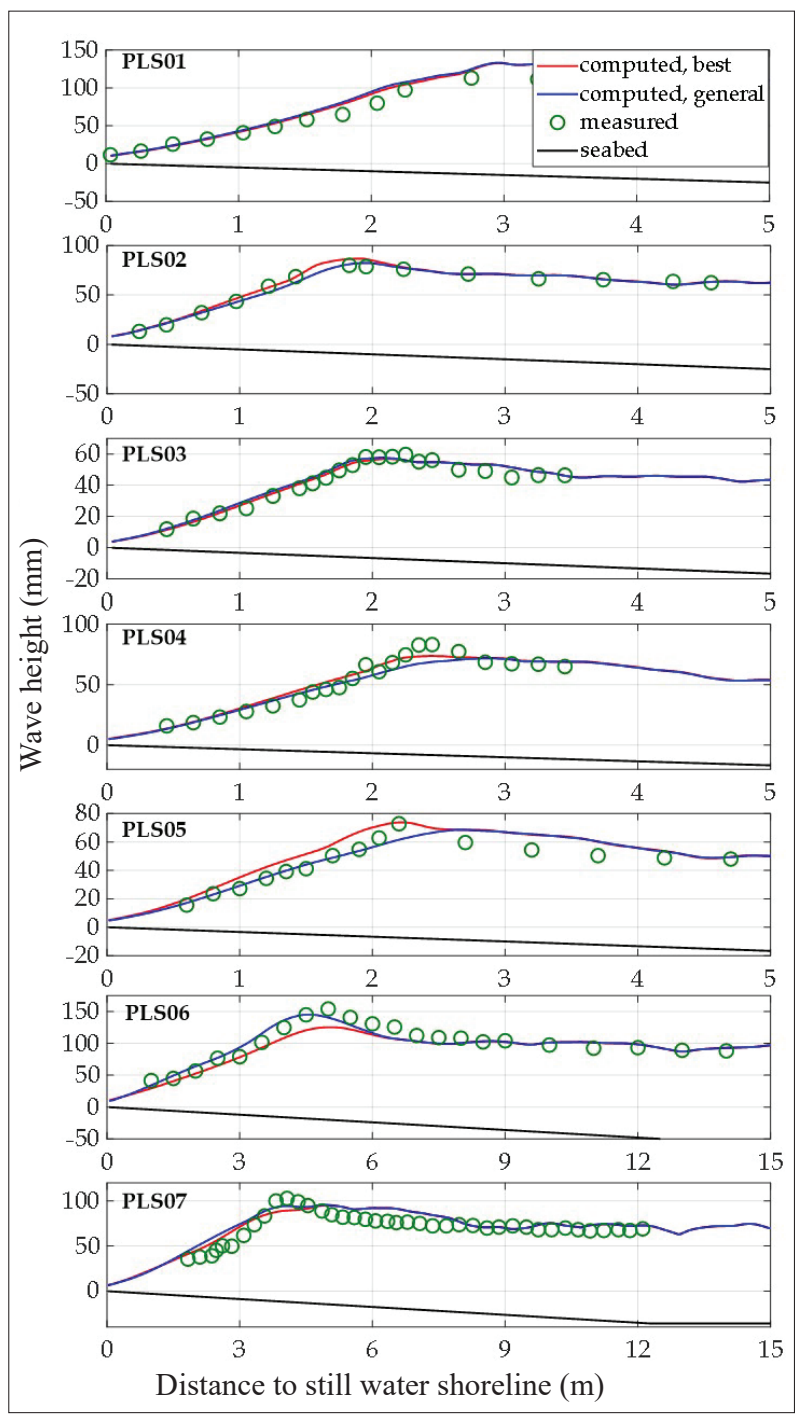

Figure 4: Wave height distribution across the surf zone (plane seabed slope) related to highest combined Willmott index, whereas the blue lines indicate the profiles associated with the proposed values for model parameters considering the overall agreement of all 8 cases. The numerical model parameters and the Willmott indices for cases associated with the best agreement with the experimental data are also listed in Table 2.

The combined Willmott index for best agreement is found to be over 0.90 for all cases with submerged structures demonstrating excellent predictive skills of the numerical model. However, the wave breaking detection parameter and mixing length, vary from 0.68 to 1.00 ,

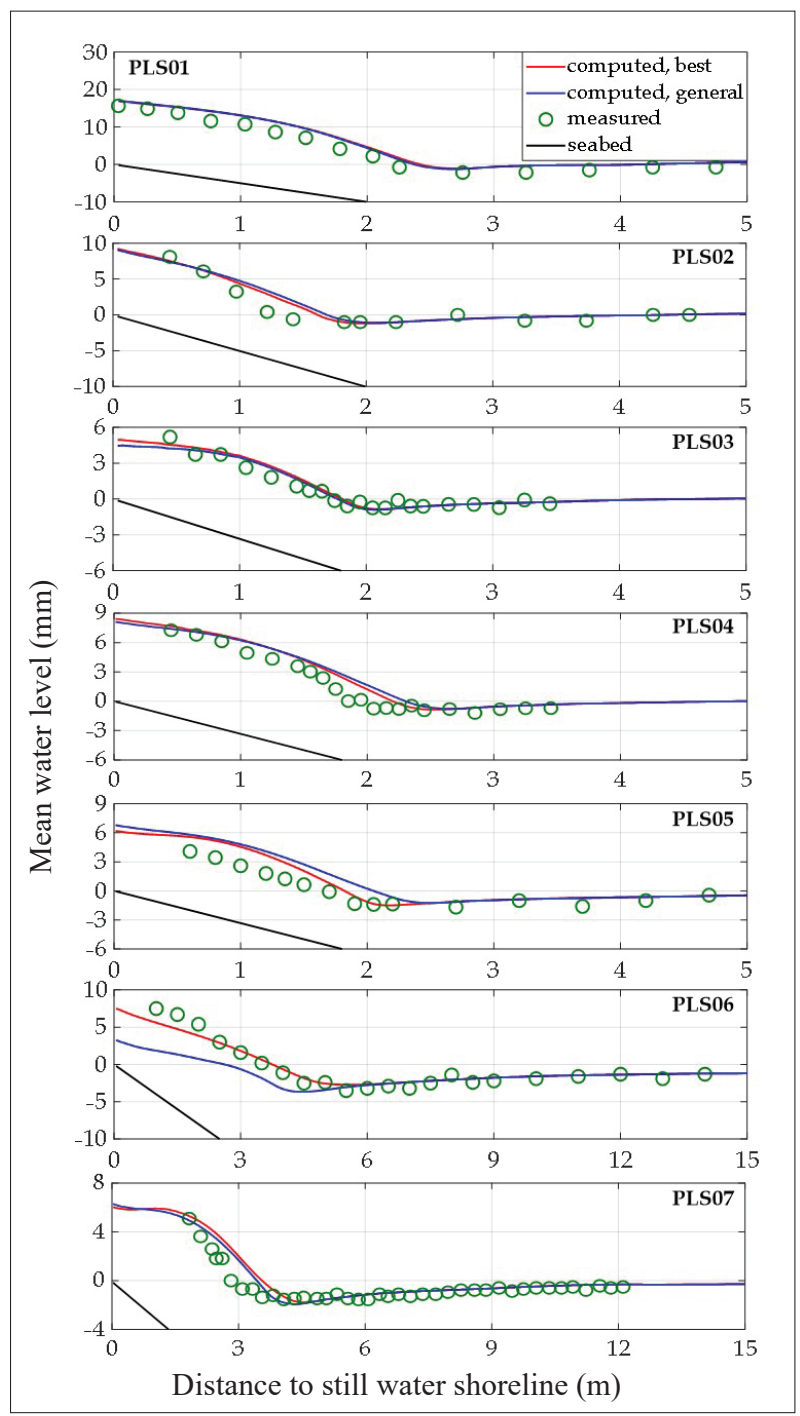

Figure 5: Mean water level distribution across the surf zone (plane seabed slope) 


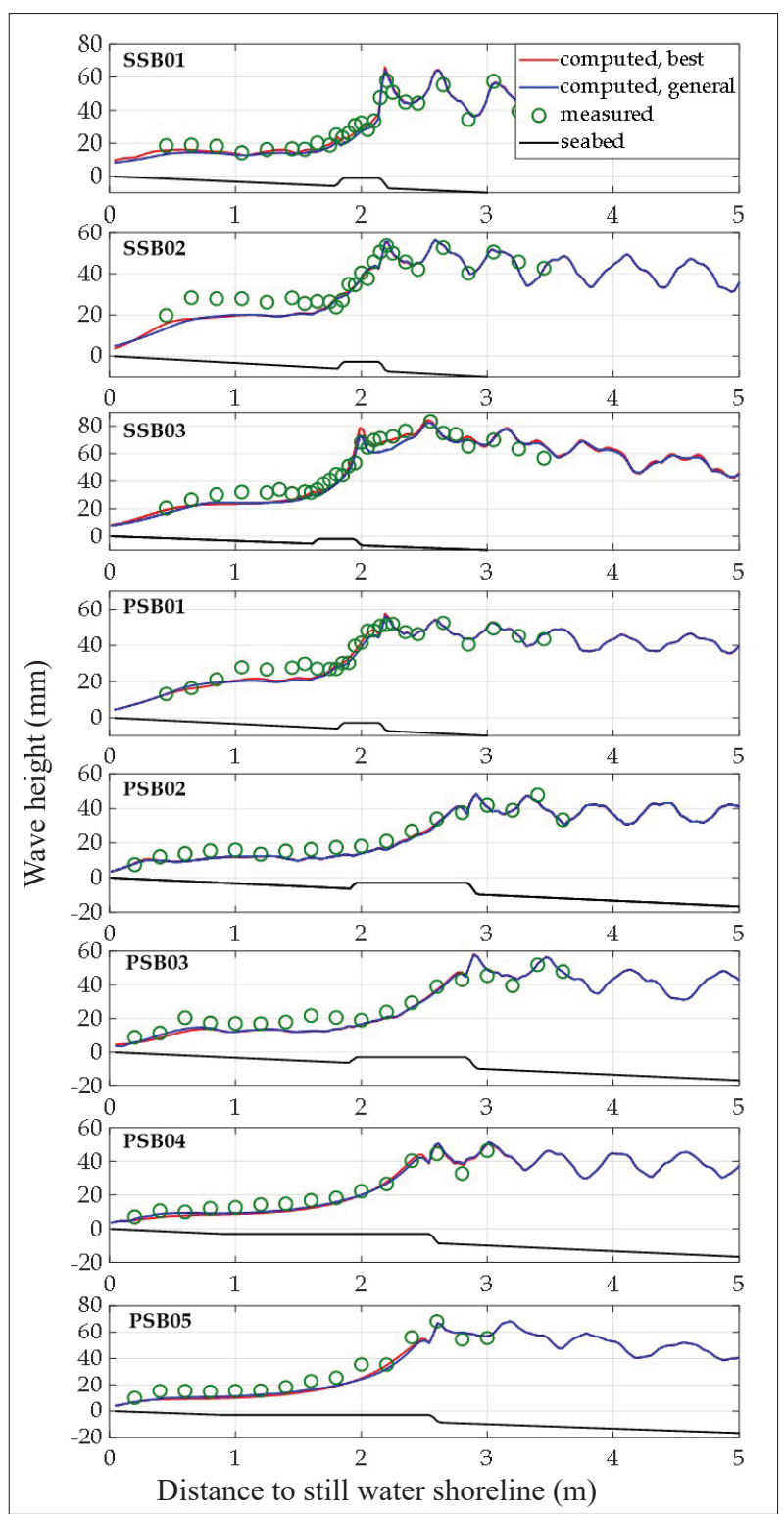

Figure 6: Wave height distribution across the surf zone (seabed with a submerged structure)

and from $0.5 \mathrm{H}_{\mathrm{i}}$ to $1.00 H_{i}$, respectively across the 8 cases tested with submerged structures.

From the results obtained by running the numerical model with different model parameters and different depth configurations, it is evident that both the wave breaking detection parameter and the mixing length, $l_{m}$ tend to be slightly smaller for cases with submerged structures in comparison to cases with plane seabed slopes. The relatively smaller mixing lengths found for submerged

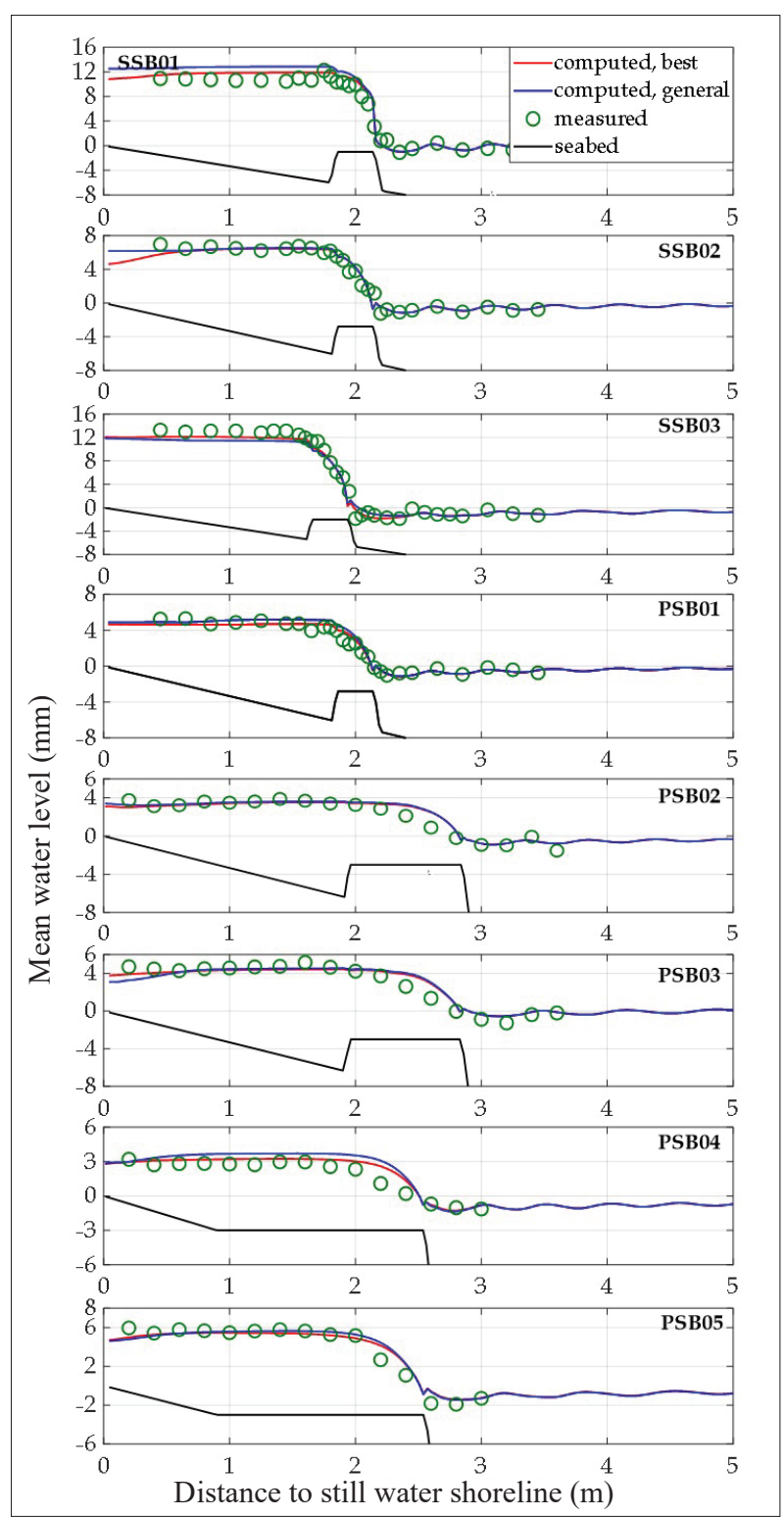

Figure 7: Mean water level distribution across the surf zone (seabed with a submerged structure)

structures are mainly attributed by the depth limitations on the crown and the relatively smaller $u^{s} / C$ observed for cases with submerged structures is due to the forced abrupt wave breaking.

\section{Model calibration}

In the present study, using the simulation results, it is attempted to propose appropriate values for wave breaking detection parameter and mixing length to make 
the model applicable to different wave environments and bottom configurations (i.e. the calibration). The model performance for conditions with plane seabed slopes and submerged structures is considered separately and the wave breaking detection parameter, $u^{S} / C$ through the calibration process is estimated to be 0.90 and 0.80 , respectively for these two bottom configurations.

Considering the turbulence generation and associated scale of turbulence, it is hypothesised in this study that the mixing length is dependent on both wave height and wave period (not just limited to wave height). As the wavelength is proportional to the wave period, mixing length, $l_{m}$ is defined as a fraction of $\sqrt{H_{i} L_{0}}$, where $L_{0}$ is the deepwater wavelength. Table 2 lists this quantity for all 15 cases and the ratio, $l_{m} / \sqrt{H_{i} L_{0}}$ is found to be slightly higher for the cases associated with plane seabed slopes in comparison to those associated with submerged structures. The average $l_{m} / \sqrt{H_{i} L_{0}}$ ratios are 0.15 and 0.09 for cases with plane seabed slopes and submerged structures, respectively (Table 3).

Table 3: Proposed breaking indices, mixing lengths and corresponding Willmott indices associated with all cases.

\begin{tabular}{|c|c|c|c|c|c|c|}
\hline \multirow[t]{2}{*}{ Case No. } & \multirow{2}{*}{$\begin{array}{l}l_{m}, \\
\mathrm{~mm}\end{array}$} & \multirow{2}{*}{$\frac{u^{s}}{C}$} & \multirow{2}{*}{$\frac{l_{m}}{\sqrt{H_{i} L_{0}}}$} & \multicolumn{3}{|c|}{ Willmott Index } \\
\hline & & & & $\begin{array}{l}\text { Wave } \\
\text { Height }\end{array}$ & $\begin{array}{c}\text { Mean Water } \\
\text { Level }\end{array}$ & Combined \\
\hline PLS01 & 69.6 & 0.90 & 0.15 & 0.9920 & 0.9695 & 0.9617 \\
\hline PLS02 & 54.6 & 0.90 & 0.15 & 0.9913 & 0.9457 & 0.9375 \\
\hline PLS03 & 38.8 & 0.90 & 0.15 & 0.9867 & 0.9723 & 0.9594 \\
\hline PLS04 & 52.4 & 0.90 & 0.15 & 0.9519 & 0.9526 & 0.9068 \\
\hline PLS05 & 50.2 & 0.90 & 0.15 & 0.9542 & 0.8651 & 0.8255 \\
\hline PLS06 & 112.5 & 0.90 & 0.15 & 0.9599 & 0.6148 & 0.5901 \\
\hline PLS07 & 81.0 & 0.90 & 0.15 & 0.8793 & 0.9222 & 0.8109 \\
\hline SSB01 & 22.2 & 0.80 & 0.09 & 0.9882 & 0.9837 & 0.9721 \\
\hline SSB02 & 22.2 & 0.80 & 0.09 & 0.9541 & 0.9624 & 0.9182 \\
\hline SSB03 & 30.8 & 0.80 & 0.09 & 0.9425 & 0.9745 & 0.9185 \\
\hline PSB01 & 22.2 & 0.80 & 0.09 & 0.9789 & 0.9903 & 0.9694 \\
\hline PSB02 & 21.1 & 0.80 & 0.09 & 0.9810 & 0.9748 & 0.9563 \\
\hline PSB03 & 26.6 & 0.80 & 0.09 & 0.9781 & 0.9494 & 0.9286 \\
\hline PSB04 & 21.3 & 0.80 & 0.09 & 0.9851 & 0.9421 & 0.9281 \\
\hline PSB05 & 28.8 & 0.80 & 0.09 & 0.9818 & 0.9740 & 0.9563 \\
\hline
\end{tabular}

As indicated earlier, the blue lines in Figures 4,5,6,7 indicate the simulated wave height and mean water level distributions after setting the wave breaking detection parameter, $u^{s} / C$ to 0.90 and 0.80 and $l_{m} / \sqrt{H_{i} L_{0}}$ ratios to 0.15 and 0.09 for cases with plane seabed slopes and submerged structures, respectively. As it can be seen from Table 3, the combined Willmott index is found to be less than 0.90 only in results obtained for cases PLS05, PLS06 and PLS07 with the calibrated model. Apart from the significant deviation observed in case PLS06 for mean water level (Figure 5), the simulated wave height and mean water distributions with proposed model parameter values show excellent agreement with experimental data.

It is noted from the simulations that the mean water levels associated with porous structures demonstrate a sudden increase over the structure when compared to observations (not prominent for PSB01 due to its short crest). Although flow through porous structures is allowed in the simulations, wave celerity calculations were performed using linear dispersion relation taking clear water depths. Since the porosity effects were not considered, wave celerity might have been 
underestimated in the simulations, which led to a slightly early and intense wave breaking.

\section{CONCLUSIONS}

Two weakly nonlinear Boussinesq-type wave models were developed, validated and calibrated using a published set of data in $1 \mathrm{DH}$. During the calibration process, wave breaking detection parameter, $u^{s} / C$ and mixing length, $l_{m}$ were varied obtaining a total of 126 simulation runs for each experimental case considered (there were 15 cases). Using the simulation results in this study, the mixing length is correlated to both wave height and wavelength considering its direct relevance to those wave parameters and is defined as a fraction of $\sqrt{H_{i} L_{0}}$. The simulation runs indicate a parametric value of 0.90 and 0.80 for $u^{S} / C$, and a non-dimensional mixing length $\left(l_{m} / \sqrt{ } H_{i} L_{0}\right)$ of 0.15 and 0.09 , for modelling of wave transformation over plane seabeds and submerged structures, respectively. The results obtained from 1DH numerical experiments show promising results for its capabilities in simulating wave evolution over different depth configurations in 2DH.

\section{REFERENCES}

Chen Q. (2006). Fully nonlinear Boussinesq-type equations for waves and currents over porous beds. Journal of Engineering Mechanics 132(2): 220-230.

DOI: https://doi.org/10.1061/(ASCE)0733-9399(2006)132 :2 (220)

Chen Q., Kirby J.T., Dalrymple R.A., Shi F. \& Thornton E.B. (2003). Boussinesq modelling of longshore currents. Journal of Geophysical Research 108: 3362-3378. DOI: https://doi.org/10.1029/2002JC001308

Chondros P.A. \& Memos O.R. (2014). A 2DH nonlinear Boussinesq-type wave model of improved dispersion, shoaling and wave generation characteristics. Coastal Engineering 91: 99-122.

DOI: https://doi.org/10.1016/j.coastaleng.2014.05.007

Cruz E.C. \& Chen Q. (2007). Numerical modelling of nonlinear water waves over heterogeneous porous beds. Ocean Engineering 34(8-9): 1303-1321. DOI: https://doi.org/10.1016/j.oceaneng.2006.03.017

Cruz E.C., Isobe M. \& Watanabe A. (1997). Boussinesq equations for wave transformation on porous beds. Coastal Engineering 30(1-2): 125-156. DOI: https://doi.org/10.1016/S0378-3839(96)00039-7

Deigaard R. (1989). Mathematical modelling of waves in the surfzone. Progress Report 69, ISVA, Technical University, Lyngby, Denmark.

Garcia N., Lara J.L. \& Losada I.J. (2004). 2D numerical analysis of near-field flow at low-crested permeable breakwaters. Coastal Engineering 51(10): 991-1020.

DOI: https://doi.org/10.1016/j.coastaleng.2004.07.017
Gobbi M.F., Kirby J.T. \& Wei G.E. (2000). A fully nonlinear Boussinesq model for surface waves, Part 2: Extension to $\mathrm{O}(\mathrm{kh})^{4}$. Journal of Fluid Mechanics 405: 181-210. DOI: https://doi.org/10.1017/S0022112099007247

Hansen J.B. \& Svendsen I.A. (1979). Regular waves in shoaling water - experimental data. Series Paper 21, Institute of Hydrodynamics and Hydraulic Engineering, Tech. Univ. Denmark.

Hsiao S.H., Liu P.L.-F. \& Chen Y .(2002). Nonlinear water waves propagating over a permeable bed. Proceedings of Royal Society of London. A 458(2022): 1291-1322.

DOI: https://doi.org/10.1098/rspa.2001.0903

Ishii T., Isobe M. \& Watanabe A. (1994). Improved boundary conditions to a time-dependent mild slope equation for random waves. Proceedings of the $24^{\text {th }}$ International Conference on Coastal Engineering, Kobe, Japan, 23-28 October. ASCE, pp. 272-284.

DOI: https://doi.org/10.1061/9780784400890.022

Johnson H.K., Karambas Th.V., Avegeris I., Zanuttigh B., Gonzalez-Marco D. \& Caceres I. (2005). Modelling waves and currents around submerged breakwaters. Coastal Engineering 52(10-11): 949-969.

DOI: https://doi.org/10.1016/j.coastaleng.2005.09.011

Karambas Th.V. \& Memos C.D. (2009). Boussinesq model for weakly nonlinear fully dispersive water waves. Journal of Waterways, Port, Coastal and Ocean Engineering 135(5): 187-199.

DOI: https://doi.org/10.1061/(ASCE)0733-950X(2009) 135:5(187)

Kennedy A.B., Chen Q., Kirby J.T. \& Dalrymple R.A. (2000). Boussinesq modelling of wave transformation, breaking and run-up, I: 1D. Journal of Waterways, Port, Coastal and Ocean Engineering 126(1): 39-47.

DOI: https://doi.org/10.1061/(ASCE)0733-950X(2000) 126:1(39)

Kirby J.T. (2003). Chapter 1 Boussinesq models and applications to nearshore wave propagation, surf zone processes and wave-induced currents. Advances in Coastal Modelling 67: 1-41.

DOI: https://doi.org/10.1016/S0422-9894(03)80118-6

Li B. (2008). Wave equations for regular and irregular water wave propagation. Journal of Waterways, Port, Coastal and Ocean Engineering 134(2): 121-142.

DOI: https://doi.org/10.1061/(ASCE)0733-950X(2008) 134:2(121)

Madsen P.A., Banijamali B. \& Schäffer H. (1996). Boussinesqtype equations with high accuracy in dispersion and nonlinearity. Proceedings of the $25^{\text {th }}$ International Conference on Coastal Engineering, Florida, USA, 2-6 September. ASCE, pp. 95-108.

DOI: https://doi.org/10.1061/9780784402429.008

Madsen P.A., Murray R. \& Sorensen O.R. (1991). A new form of the Boussinesq equations with improved linear dispersion characteristics. Coastal Engineering 15(4): 371-388. DOI: https://doi.org/10.1016/0378-3839(91)90017-B

Madsen P.A. \& Schäffer .H.A. (1998). Higher-order Boussinesqtype equations for surface gravity wave: derivation and analysis. Philosophical Transactions of the Royal Society 
of London A: Mathematical, Physical and Engineering Sciences 356(1749): 3123-3181.

DOI: https://doi.org/10.1098/rsta.1998.0309

Madsen P.A. \& Sorensen O.R. (1992). A new form of the Boussinesq equations with improved linear dispersion characteristics, Part 2: A slowly-varying bathymetry. Coastal Engineering 18 (3-4): 183-204.

DOI: https://doi.org/10.1016/0378-3839(92)90019-Q

Metallinos A.S., Repousis E.G. \& Memos C.D. (2016). Wave propagation over a submerged porous breakwater with steep slopes. Ocean Engineering 111: 424-438.

DOI: https://doi.org/10.1016/j.oceaneng.2015.11.015

Nwogu O.G. \& Demirbilek Z. (2001) Bouss-2D: A Boussinesq model for coastal regions and harbours. Technical Notes, US Army Corps of Engineers.

Nwogu O.J. (1993). Alternative form of Boussinesq equations for nearshore wave propagation. Journal of Waterways, Port, Coastal and Ocean Engineering 119(6): 618-638. DOI: https://doi.org/10.1061/(ASCE)0733-950X(1993)119: 6(618)

Nwogu O.J. (1996). Numerical prediction of breaking waves and currents with Boussinesq model. Proceedings of the $25^{\text {th }}$ International Conference on Coastal Engineering, Florida, USA, 2-6 September. ASCE, pp. 4807-4820. DOI: https://doi.org/10.1061/9780784402429.374

Ranasinghe R.S. (2018). Numerical modelling of wave transformation over submerged breakwaters using Boussinesq-type models. Journal of the National Science Foundation, Sri Lanka 46(3): 369-379.

DOI: http://doi.org/10.4038/jnsfsr.v46i3.8488

Ranasinghe R.S. (2020). A comparative study of eddy viscosity models for simulating wave breaking induced energy dissipation in Boussinesq models. Engineer: Journal of the Institution of the Engineers, Sri Lanka 53(2): 1-12. DOI: http://doi.org/10.4038/engineer.v53i2.7407

Ranasinghe R. S., Sato S. \& Tajima Y (2009a) Boussinesq modelling of waves and currents over submerged breakwaters. Proceedings of the $5^{\text {th }}$ International Conference on Asian and Pacific Coasts, Singapore, 13-16 October. DOI: https://doi.org/10.1142/9789814287951 0097

Ranasinghe R.S., Sato S. \& Tajima Y. (2009b). Modelling of waves and current around porous submerged breakwaters. CD Proceedings Coastal Dynamics 09', Tokyo, Japan, 7-11 September. DOI: https://doi.org/10.1142/9789814282475_0015

Ranasinghe R.S., Fukase Y. Sato S. \& Tajima Y. (2011). Local concentration of waves due to abrupt alongshore variation of nearshore bathymetry. Coastal Engineering Journal 53(3): 201-222.

DOI: https://doi.org/10.1142/S0578563411002331

Sato S., Fukuhama M. \& Horikawa K. (1988). Measurements of near-bottom velocities in random waves on a constant slope. Coastal Engineering in Japan 31(2): 219-229. DOI: https://doi.org/10.1080/05785634.1988.11924494

Schäffer H.A. (2004). Another step toward a post-Boussinesq model. Proceedings of the $29^{\text {th }}$ International Conference on Coastal Engineering, Lisbon, Portugal, 19-24 September. ASCE, pp. 132-144.

DOI: https://doi.org/10.1142/9789812701916_0009

Schäffer H.A., Madsen P.A. \& Deigaard R. (1993). A Boussinesq model for wave breaking in shallow water. Coastal Engineering 20(3-4): 185-202.

DOI: https://doi.org/10.1016/0378-3839(93)90001-O

Siddique M., Merabtene T. \& Tajima Y. (2017). Wave transformation and hydrodynamic characteristics of wave breaking models coupled with Boussinesq equations. Journal of Hydraulic Research 55(6): 759-771. DOI: https://doi.org/10.1080/00221686.2017.1289261

Sollitt C.K. \& Cross R.H. (1972). Wave transmission through permeable breakwater. Proceedings of the $13^{\text {th }}$ International Conference on Coastal Engineering, Vancouver, Canada, 10-14 July. ASCE, pp. 1827-1846.

DOI: https://doi.org/10.9753/icce.v13.99

Svendsen I.A. (1984). Wave heights and set-up in a surf zone. Coastal Engineering 8(4): 303-329.

DOI: https://doi.org/10.1016/0378-3839(84)90028-0

Tajima Y., Sato S., Shimozono S. \& Isobe M. (2007). Modelling of wave induced current around submerged detached breakwaters. Proceedings of Coastal Structures '07, Venice, Italy, 2-4 July. ASCE, pp. 725-736.

DOI: https://doi.org/10.1142/9789814282024_0064

van Gent M.R.A. (1995). Porous flow through rubble-mound material. Journal of Waterways, Port, Coastal and Ocean Engineering 121(3): 176-181.

DOI: https://doi.org/10.1061/(ASCE)0733-950X(1995) 121:3(176)

Wei G. \& Kirby J.T. (1995). Time dependent numerical code for extended Boussinesq equations. Journal of Waterway Port, Coastal and Ocean Engineering 121(5): 251-261. DOI: https://doi.org/10.1061/(ASCE)0733-950X(1995) 121:5(251)

Wei G.E., Kirby J.T., Grilli S.T. \& Subramanya R. (1995). A fully nonlinear Boussinesq model for surface waves, Part 1: Highly nonlinear unsteady waves. Journal of Fluid Mechanics 294: 71-92.

DOI: https://doi.org/10.1017/S0022112095002813

Willmott C.J. (1984). On the validation of models. Physical Geography 2: 184-194.

DOI: https://doi.org/10.1080/02723646.1981.10642213

Zelt J.A. (1991). The run-up of nonbreaking and breaking solitary waves. Coastal Engineering 15(3): 205-246. DOI: https://doi.org/10.1016/0378-3839(91)90003-Y

Zou Z.I. (1999). Higher-order Boussinesq equations. Ocean Engineering 26(8): 767-792.

DOI: https://doi.org/10.1016/S0029-8018(98)00019-5 